\title{
DATA DRIVEN PRODUCT PORTFOLIO ANALYSIS OF ELECTRIC MOTORS BASED ON PRODUCT PLATFORMS USING KNOWLEDGE-BASED SYSTEMS
}

\author{
Tüchsen, Johann (1,2); Pop, Adrian-Cornel (2); Koch, Matthias (2); Schleich, Benjamin (1); \\ Wartzack, Sandro (1) \\ 1: Friedrich-Alexander-Universität Erlangen-Nürnberg; 2: Brose Fahrzeugteile GmbH \& Co. KG
}

\begin{abstract}
For a company it is necessary to know, which products can be configured using carry-over-parts or the same technology. This can become quite relevant in the context of automobile electrification, where complex mechatronic systems are used. Consisting of various mechanical components, these systems perform the required function while being actuated by electronically controlled motors. To solve this, a novel mechanism for data driven portfolio analysis based on product platforms using knowledge-based systems is proposed in this paper. Further, the mechanism is tested by applying it to an electrical motors' case study. Using this method, all possible combinations of a product platform are calculated and finally displayed in different product portfolios. Additionally, all the non-feasible motor designs are removed from the solutions portfolio using the acquired knowledge base and performing design checks. The latter are employed for penalising and eliminating from the pareto-front of the designs, which violate the thermal, mechanical and acoustic constraints. The generated product portfolio can be used further to expand the systems engineering collaboration and support decision-making.
\end{abstract}

Keywords: Knowledge-Based Systems, Electric Motors, Platform strategies, Portfolio management, Knowledge management

Contact:

Tuechsen, Johann

Friedrich-Alexander-Universität Erlangen-Nürnberg

Engineering Design

Germany

tuechsen@mfk.fau.de

Cite this article: Tüchsen, J., Pop, A.-C., Koch, M., Schleich, B., Wartzack, S. (2019) 'Data Driven Product Portfolio Analysis of Electric Motors Based on Product Platforms Using Knowledge-Based Systems', in Proceedings of the 22nd International Conference on Engineering Design (ICED19), Delft, The Netherlands, 5-8 August 2019. DOI:10.1017/ dsi.2019.260 


\section{INTRODUCTION}

Nowadays, the electrification of automobiles is one of the key tasks that the original equipment manufacturers (OEM) as well as their suppliers must consider. In addition to the traction drive, a huge variety of previously mechanically-actuated functions are being electrified. Aside from the supporting behaviour functions of the car (such as the electric oil/water pump and braking system), modern vehicles are becoming increasingly equipped with electrified systems to reduce $\mathrm{CO} 2$ (e.g. power steering), or comfort-based features such as window regulators and door openers (see Figure 1). The primary goal of electrification within cars is to increase over efficiency whilst decreasing weight (Pop et al., 2017).

The mechatronic systems used within automobiles consist of various mechanical parts performing the required functions, while being actuated by electronically controlled electric motors. A common electric motor concept is the inner-rotor brushless three-phase permanent magnet synchronous machine (PMSM). The main components of this motor design are the stator, rotor, coils and magnets (Miller, 2002). Firstly, the stator and mounted copper coils produce the magnetic field as current flows through the wires. Within the rotor, the magnetic field interacts with permanent magnets, usually made from rare earth materials. Assuming correct coordination of this interaction, the rotor rotates on the pivoted shaft, producing torque. In order to reduce eddy current, both the stator and rotor are formed of laminated cores. The number of laminations and hence motor length can be varied within defined bounds. Also the diameter and magnetic circuit can be scaled. Due to this, electric motors can be developed using product platforms.

Different systems with similar architectures can contain the same combined motor components or at least the same motor in order to save costs and product development efforts. For a company it is necessary to know which products can be configured using carry-over-parts or -technologies. The development and analysis of the product portfolio for the design specification rather than for point solutions can aid in maintaining design flexibility (Simpson et al., 2009). Additionally, visualisation of the product portfolio creates transparency, promotes synchronisation and supports decision making (Ponn, 2015). While in economics portfolios are used to derive company strategies mostly from qualitative data (Grünig and Kühn, 2018), in the engineering community the focus lies on the products and solutions themselves (Jiao et al., 2007). The portfolio can be further analysed to optimise the product platform and detect gaps or areas of intersection.

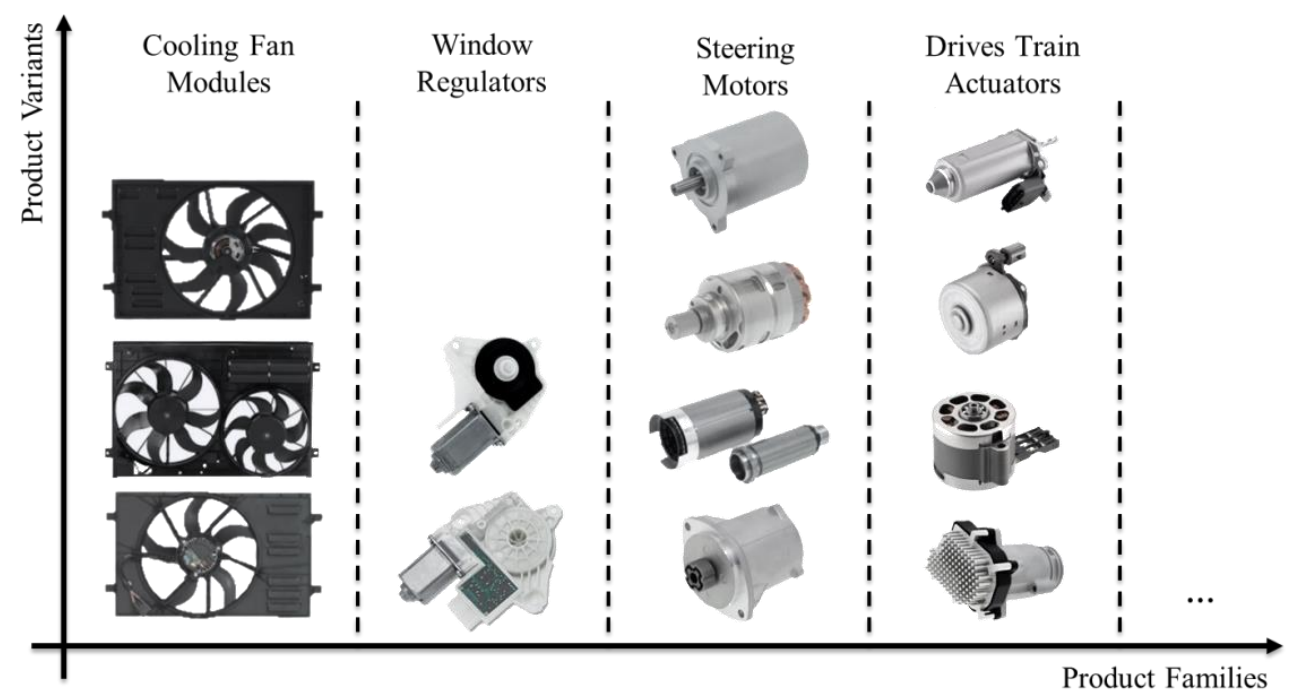

Figure 1. Example product portfolio of an automotive component supplier (Brose Fahrzeugteile GmbH \& Co. KG, 2018)

The objective of this work is to develop a solution for data driven portfolio generation providing suitable design solutions, which can be used further for portfolio analysis. The hypothesis of this work is that the use of a knowledge-based system in combination with product platform approaches can fulfil the objective of automated creation and visualisation of engineering product portfolios. The scientific novelty can thereby be found in the application of knowledge-based engineering methods to portfolio analysis. The optimisation of given portfolios and product platforms is a complex activity 
and is out of the scope of this research work. For further information on this, refer to Kumar et al. (2009), Ortlieb and Runge (2017) or Kissel (2014).

This paper is structured with four chapters. Following the introduction given in Chapter 1, the state of the art and related work is presented in Chapter 2. Subsequently, Chapter 3 presents the novel method for data driven product portfolio analysis of electric motors using product platforms and knowledgebased systems. Finally, conclusions and suggestions for future work are given in Chapter 4.

\section{STATE OF THE ART AND RELATED WORK}

Before answering the given research question, the state of the art and the related work are presented. In this context, Section 2.1 provides a brief introduction into the product portfolio management as well as common platform strategies. Following this, the concept of the knowledge-based development is presented in Section 2.2 with a short summary of the existing approaches in electric motor development.

\subsection{Product portfolio management and platform strategies}

Within the literature, there are various interpretations of product portfolio and product portfolio management. Firstly, there is the economic perspective, which focuses on the market, competitors and the relative market share of each product. The data generated is mostly qualitative and can be visualised for example in BCG-Matrices (Boston Consulting Group). Based on these portfolios, strategies to handle products or product families individually can be derived (e.g. Grünig and Kühn, 2018). Alternatively, in the engineering community the product portfolio focuses on the products and solutions offered by a company (Jiao et al., 2007). The product portfolio can be classified by the number of different product families (program width), as well as by the number of different variants (program depth) (Renner, 2007). Figure 1 shows an example of a product portfolio consisting of four different product families.

According to Meyer and Lehnerd (1997), product families share common technologies and address related sets of market applications. Furthermore, each product family has its own product architecture, which Ulrich (1995) defined as the arrangement of functional elements, their mapping to physical components and the specification of the interfaces among interacting physical components. Different design solutions for product families can be generated based on the shared product platforms (Jiao et al., 2007). A product platform is a set of common components, modules, or parts from which a stream of derived products can be efficiently created and launched (Meyer and Lehnerd, 1997). Hence, for product portfolio management product families and product platforms play a central role (Ponn, 2015). The first given example of an electric motor product platform was the electric motor within a power tool reported by Meyer and Lehnerd (1997). Simpson et al. (1999) used the universal electric motor example in their product platform concept exploration method for product family design. Kumar et al. (2009) also used the same example in order to find the optimised, market-oriented product family design. Finally, Kissel (2014) and Ponn (2015) focused on product family design for consumer power tools using the electric motor platform. The electric motor is frequently used as an example of a product platform due to the scalability; this is a key requirement of a platform-based product development approach as a high proportion of market requirements can be met by altering one or more of the variant dimensions within the platform (Jiao et al., 2007).

Briefly summarised, the electric motor can be a component of more than one product family. Within one product platform, different variants can be created by varying dimensions such as the axial length or the ampere-turns of the motor. In this way, it is possible to meet a range of customer requirements and design more than one (family-based) product on the same motor platform. In order to offer new product variants or even new product families in the overall product portfolio, there is the need to adapt the electric motor platform until it meets the new requirements. Therefore, the portfolio of the electric motor platform must be visualised and analysed, which is also the focus of this work.

According to the conceptual method for exploring a product platform proposed by Simpson et al. (1999), there are five steps in creating a product platform portfolio (see Figure 2). 


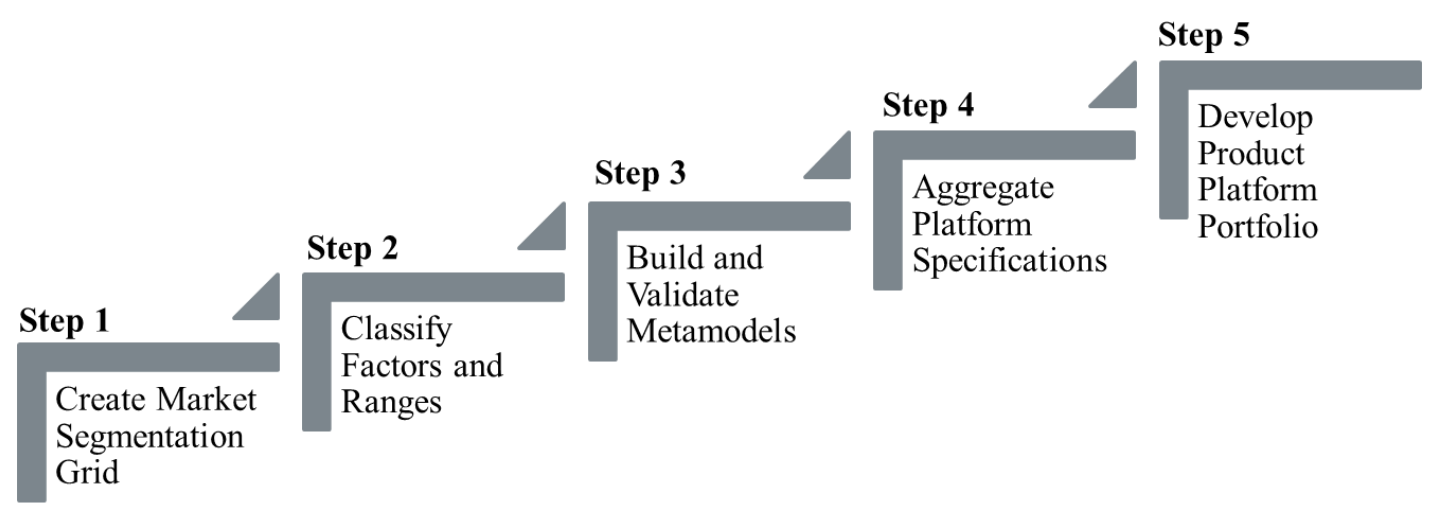

Figure 2. The Product Platform Concept Elaboration Method by Simpson et al. (1999)

The market segmentation grid (step 1) provides the link between management, marketing and design engineers and helps to identify potential opportunities for horizontal and vertical leveraging, or a beachhead approach to product platform design. The classification of factors and ranges (step 2) in which the platform has to operate are essential in evaluating the product portfolio. Using metamodels, the final product can be calculated (step 3). Step 4 takes into account the requirements from the market, which are clustered in the market segmentation grid. Finally, step 5 results in the product platform portfolio which is the sum of permissible point solutions provided by the metamodel (Simpson et al., 1999).

In the process described above, the metamodel (step 3) is critical. In accordance with Simpson et al. (1999), metamodels are needed for mathematical design estimation in the event that computational analysis or simulation is too expensive or time-consuming. In the product platform concept elaboration method by Simpson et al. (1999), no metamodel was employed due to the use of analysis equations, which directly relate specifications to systems responses. This approach covers the motor design more naturally with continuous design variables. Use of a metamodel allows for discretised motor design. In addition to explicit formulas, rules and relations are used in such a metamodel. In this work, the integration of design knowledge is focused on generating designs with improved reliability through the use of implicit and heuristic knowledge. The knowledge-based product development stage of this process is presented in the next chapter.

\subsection{Knowledge-based product development}

The availability of high quality knowledge at the right time is a key component concerning product development. Originally, experts perform problem-solving or decision-making tasks manually using personal experience and preferences. In order to digitalise and automate recurring tasks as well as to support the developer, it is common to use Knowledge-Based Systems (KBS) (Studer et al., 1998). These knowledge technologies have the benefit of combining different ideas and applications from different domains such as psychology, philosophy, artificial intelligence, engineering, business management, computer science and web technologies (La Rocca, 1997). KBS use this acquired knowledge and present it to the developer in a single architecture. Existing approaches and applications of using data mining for automated knowledge acquisition in modern product development process are presented by Breitsprecher et al. (2015). The KBS architecture usually consists of the elements user interface (UI), inference mechanism, knowledge base, knowledge acquisition, explanation and context facility (Styczynski et al., 2017). Particularly applied to the development of electric drives, there are a couple of different approaches for using KBS, where a through state-of-the art was performed in (Tüchsen et al., 2018a).

Product platforms can be used to create products through web-based product design generators, as shown by Roach and Cox (2006). Product configurators are a common approach in product development and can cut development time down from several days to less than a day (Haug et al., 2011). Forza and Salvador (2002) presented with their work of a knowledge-based product configurator for power transformers. Jinsong et al. (2005) described knowledge-based product configurators using an objectoriented modelling approach. Although product configurators contain huge amounts of knowledge about the product architecture and manufacturing process, in most cases these configurators are only able to provide pre-programmed solutions from a limited number of pre-calculated combinations. 
Overall, knowledge-based development is a well-known method in the electric motor sector as well as in the product configuration discipline. Tüchsen et al. (2018b) present a platform-, web- and knowledge-based product design generator, namely the design selector and generator (DSG), which calculates solutions in real time instead of using pre-defined configurations. In this work, geometrically fixed 2D-cross-sections (CS) of the motors are stored in a design database. Using a knowledge-based generator, more than one motor (a so-called 'design') can be derived from each CS (see Figure 3). This 3D-motor development mechanism was further implemented in the Drives Development Assistance System presented by Tüchsen et al. (2018a). This KBS is based on a central SQL database, containing all product characteristics in parametric form (e.g. geometric parameters). These parameters are further structured to describe the logic and the functions of the product. Based on the defined requirements, the KBS uses explicit equations including heuristic factors, reduced order simulation models, semantics or graphs to assist the designer with each development step. Knowledge from different departments such as production, management accounting, development and test is included in the inference mechanism and is presented to the designer through the web-based user interface. Any communication during the product development process is performed via the KBS.

One module of the KBS is the electro-mechanic designer, which enables design calculations within defined degrees of freedom based on pre-calculated design tables. According to Meyer and Lehnerd (1997), Ponn (2015) and Pop et al. (2017), the length of the motor can be varied by stretching/scaling within the KBS. The winding parameters which include wire diameter, the number of turns and the winding scheme (i.e. number of parallel branches) are degrees of freedom (DoFs) and are used for product variation. Materials can also be changed within the defined design area.

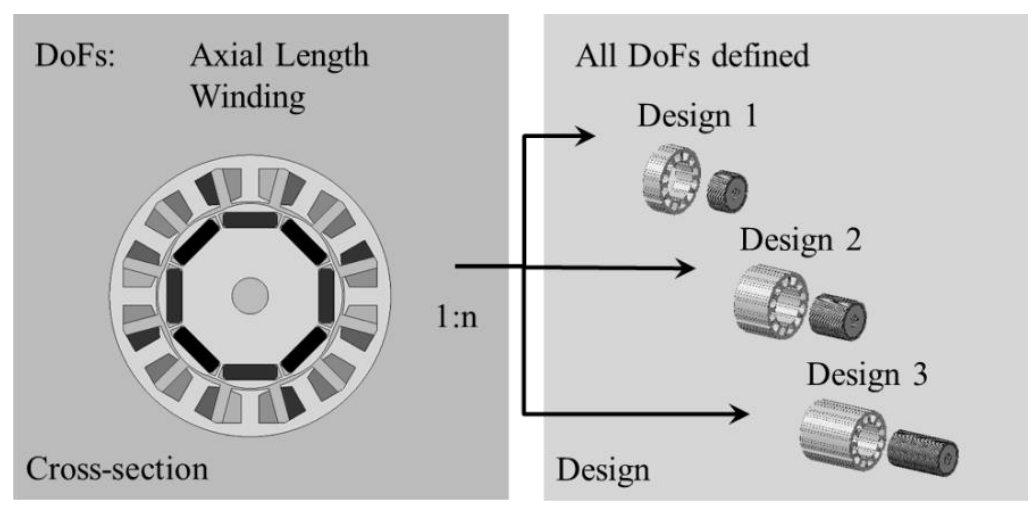

Figure 3. Platform relationship between cross-section and design (Tüchsen et al., 2018b)

In principle, the development tools and scripts based on explicit formulas and the resulting product platform yield a huge amount of combinations, however not all these combinations are feasible. Therefore, the explicit knowledge is extended by implicit knowledge in order to take into account the manufacturing process, design guidelines and overall goals of the company. The designs are further checked for thermal, acoustic and mechanical behaviour and only designs fulfilling all these criteria are allowed to pass (Tüchsen et al., 2018c). Additionally, a simulation based approach for taking into account geometric deviations and deformations presented by Walter et al. (2011) could be considered to identify solutions which meet the customer requirements.

\section{DATA DRIVEN PRODUCT PORTFOLIO ANALYSIS OF ELECTRIC MOTORS USING PRODUCT PLATFORMS AND KNOWLEDGE-BASED SYSTEMS}

Although the concepts of portfolio management, product platforms and KBS are well studied within each discipline, a continuous solution for data driven portfolio analysis, which only provides suitable solutions has not yet been presented within the literature. Therefore, this work proposes a method based on product platforms and KBS, which leads to data driven product portfolio development and analysis. First, the overall architecture of the presented mechanism is given in Section 3.1, highlighting the process and the necessary steps. In Section 3.2, the five step method for exploring a product platform (presented in Section 2.1) is applied to the development of a portfolio for automotive electric motors. Additionally, the results of the portfolio are presented and analysed in this section, while Section 3.3 contains a critical discussion of these results. 


\subsection{Overall mechanism for portfolio creation}

The overall mechanism developed in this work is presented in Figure 4. The method uses a database containing the geometrically fixed CS. All CS are part of the motor platform and are used by the KBS to create different motors (designs) by varying defined DoFs. The KBS was designed for fast provision of motor designs which are optimised for cost and efficiency with parts for standardised manufacturing (Tüchsen et al., 2018b). Rather than varying the DoFs to identify the most suitable motor, a broad design of experiments (DoE) is used to calculate all possible configurations for the given (existing) platform. By using real time calculations and a fully configured (with rules) decision making process, the algorithm inside the inference mechanism of the KBS generates all possible design solutions. The system eliminates all non-optimal solutions (i.e. technically or economically not feasible) from the pool of solutions with the use of the knowledge-base. For example, the given space in the stator area is fixed and cannot be exceeded. This results in a maximum number of possible winding for each wire diameter and has to be considered as a condition for the DoFs of varying the number of windings. Additional checks are performed to ensure that only designs fulfilling the thermal, acoustic or mechanical constraints are presented (Tüchsen et al., 2018c). Finally, by fixing the other dimensions, all motor designs can be visualised in two-dimensional scatterplots using technical key performance indicators (KPIs) or customer requirements (See Figure 4).

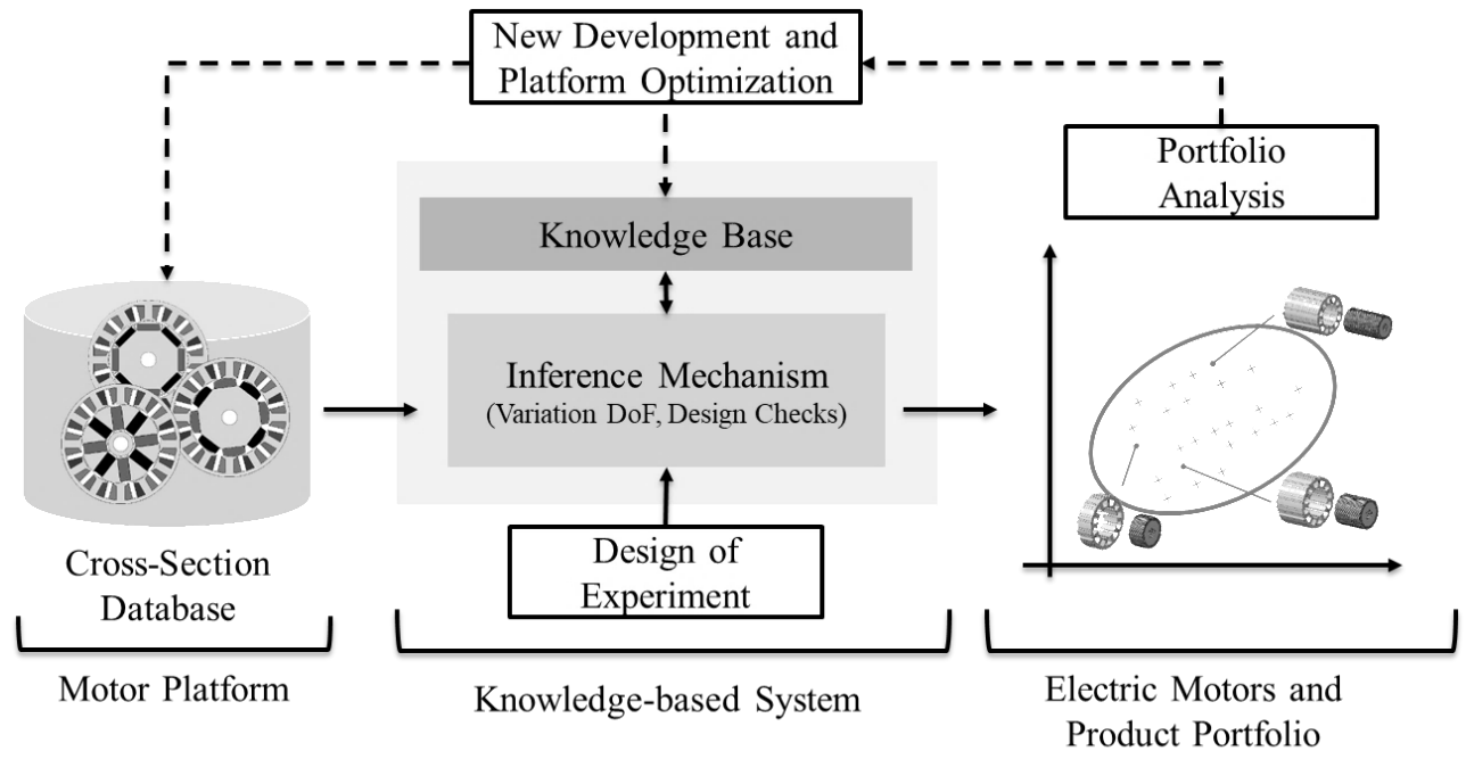

Figure 4: Overall mechanism for data driven product portfolio analysis using product
platforms and knowledge-based systems

Based on the real-time calculated motor portfolios, decisions related to the company strategy can be derived. In addition, visualisation offers the opportunity for analysis: The user is able to check if the CS-clustered design results intersect or if there are gaps in the portfolios that must be filled in. All customer requests and requirements can be stored and visualised in the product portfolios and these can be used to track changes in existing or new markets over time. Finally, various methods for platform optimisation can be implemented in this process as shown in Figure 4 in order to obtain a market-optimised product portfolio.

Thanks to its modular approach, the proposed structure allows the addition of new CS, technologies and knowledge as well as real time updates to visualise changes in the platform, portfolio or customer requirements. Thus, this approach is sustainable and future-oriented and can be used for responsible decision making. A dynamical web-based UI facilitates the creation of templates (i.e. user-dependent portfolio graphs) based on all calculated values and stored requirements.

\subsection{Product portfolio analysis on the example of electric drives}

The five steps described by Simpson et al. (1999) and briefly presented in Section 2.1 (namely: market segmentation, classification of factors and ranges, build and validate metamodels, aggregation of platform specifications and finally, the development of the product platform portfolio) are applied with the proposed architecture in order to present its functionality. 


\subsubsection{Market segmentation}

The first step is to separate the existing product portfolio into different product families to address different markets (horizontal leveraging, as shown in Figure 1). Vertical leveraging is not necessary in the given case study, as the differences within a product family are marginal. In this work, the requirements of the two product families, drive train actuators (DTA) and electric power steering (EPS) are applied on four motor CS where CS1 and CS2 belong to the first product family and CS3 and CS4 belong to the second. The four CS differ in size and geometry by the number and position of the teeth and magnets, as well as in the materials and manufacturing technologies implemented.

\subsubsection{Classification of factors and ranges}

The second step is dedicated to the definition of the scale factors (i.e. the DoFs). As previously described, the stack length of the motor and the ampere-turns of the winding are key DoFs in meeting performance requirements. These DoFs are further used in the DoE to generate all possible combinations permitted by the product platform. Therefore, a full factorial DoE is performed by varying the stack length of the four different CS from $10 \mathrm{~mm}$ to $60 \mathrm{~mm}$ (in increments of $10 \mathrm{~mm}$ ) and the number of turns from 5 to 50 (in increments of 1). The ranges used in the DoE and the discretisation method are variable. The full factorial sample generation method is considered to be the best trade-off between calculation time and accuracy when considering two DoFs of the resulting motors.

\subsubsection{Metamodelling}

The mathematical description of the product platform including all defined DoFs results in a metamodel. The KBS that was previously described in Section 2.2 is proposed for use. As a high filling factor is an inherent part of any optimal machine design (Pop et al., 2017), based on the stored knowledge in the backend, the KBS automatically chooses the biggest manufacturable wire diameter along with the winding process to meet the optimal cost/performance criteria.

\subsubsection{Aggregation of platform specifications}

The fourth step is essential to gain relevant portfolio diagrams. Requirements will differ depending on the market segmentation of product families. For an EPS motor, low relative torque ripple (peak-topeak value related to the average mechanical torque $T_{r i p} / T_{\text {mech }}$ ) and low noise and vibration and harshness $(\mathrm{NVH})$ are mandatory requirements. These requirements are low-rated in the products belonging to DTA-family so the performance/cost ratio becomes of prime importance. General requirements for all electric motors are high efficiencies in the defined working points as well as low weight, which results in less material usage and inherently, low active material costs. As the motor operation is dependent on parameters such as operating voltage, current, temperature as well as transient or continuous working points with defined torque and speed combinations, more general key performance indicators must be used for motor comparison. If there is no specific customer requirement, it is beneficial option to show the maximum power $P_{\max }$ of the motor and its torque-speed characteristic at a defined battery voltage and current. Traditionally in the automotive sector most motors are actuated using a $12 \mathrm{~V}$ vehicle electrical energy supply, hence the portfolios in this paper are generated in line with this.

For electric drive development, achieving high efficiency is crucial. Beside the input parameters, efficiency can be influenced by the pair speed and torque. This makes it difficult to compare motors of different power classes and sizes (as typical within a product portfolio). In order to solve this, Wang et al. (2015) introduced a global factor of badness $B$ to establish a basis for the comparison between different machines and designs. This factor is calculated using the total motor losses $W_{\text {Loss }}$. which are produced when developing the shaft torque $T$ :

$$
B=\frac{\sqrt{W_{\text {Loss }}}}{T} .
$$

Another important key iicator used for the portfolio analysis is the relative torque ripple $\left(T_{r i p} / T_{\text {mech }}\right)$.

\subsubsection{Development of the product platform portfolio}

After the definition of the KPIs for the product platform, the portfolios are created by using the DoE and the KBS. For all portfolios in this work, battery current was limited to $100 \mathrm{~A}$ and voltage was set to 
$12 \mathrm{~V}$. In this example, the results of $B, T_{r i p} / T_{\text {mech }}$ and Costs are tan at the point of constant maximum power $P_{\max }$ and are drawn in several two-dimensional scatterplots. The first portfolio (Figure 5, left) shows all results of the full factorial DoE for the first two CS. Here, the designs, which will be filtered out because they are violating the thermal, acoustic or mechanic constraints are shown with a different marker compared to the valid designs. They can mainly be seen on the upper and right-hand side of Figure 5, left. This portfolio shows the huge relevance of using a KBS for calculation-based platform configuration as more than the half of the solutions of the DOE are not feasible.
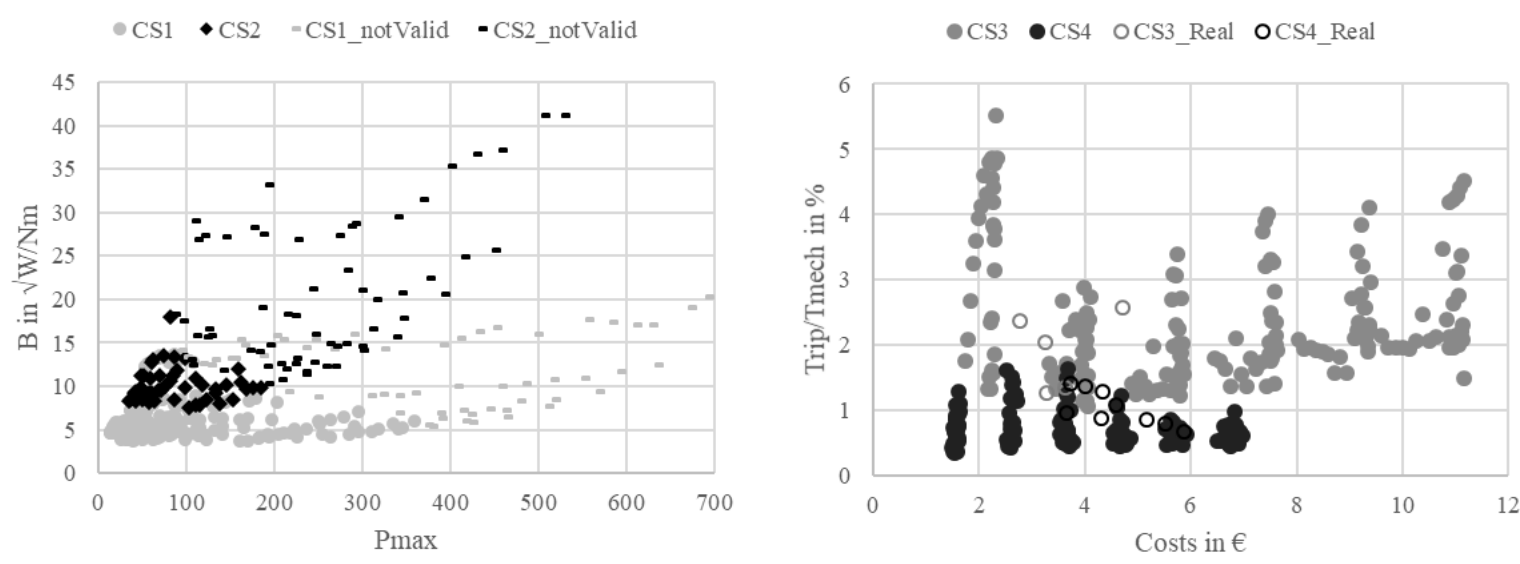

Figure 5. Valid and non-valid designs resulting from the DoE (left) and valid designs including already existing design solutions (right)

In addition, configurations of already produced motors can be highlighted in the given portfolio in order to evaluate the common products area. For the EPS product family, there are 14 different motor designs commercially used based on CS3 and CS4 (Figure 5, right). This portfolio highlights that not the all feasible designs have been utilised. Furthermore, it can be gathered that the customer requirements for existing EPS-motors are quite similar with values ranging from $0.8 \%$ to $3 \%$ for $T_{r i p} / T_{\text {mech }}$ and from $3 €$ and $5 €$ for active material costs. This unused range could be exploited by a new product family.
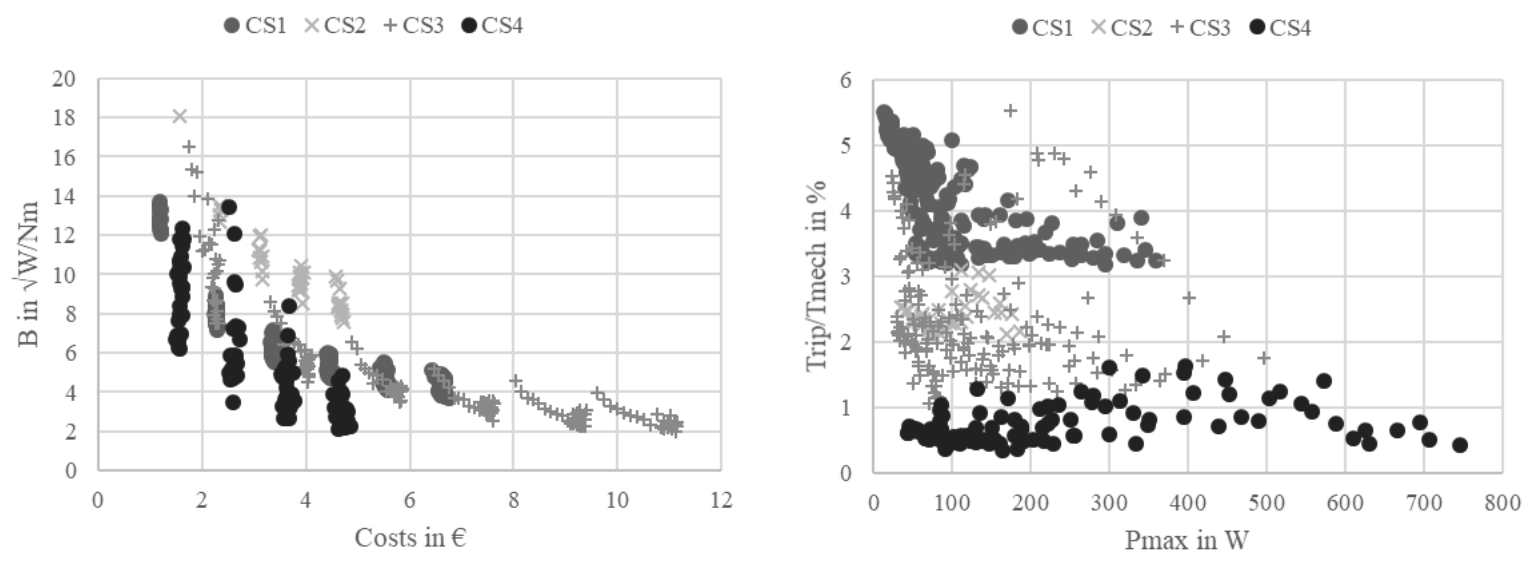

Figure 6. Portfolios of factor of badness over costs (left) and torque ripple over power (right)

The next portfolio (Figure 6, left) shows the calculated factor of badness as function of the active material costs. Here it can be seen that the lower the factor of badness is (which means higher efficiencies), the higher the costs. This trend is similar for all given CS. Additionally it can be seen, that the CS usually designed for EPS application (CS3 and CS4) are reaching lower factors of badness than the CS that are usually designed for DTAs (CS1 and CS2). This can be explained by the fact that the EPS-motors have larger diameters than the DTA ones. Although CS1 and CS2 also reach low badness values at active material costs around $4 €$ (longer machines), they are not suitable for EPS applications due to high (relative) torque ripple values shown in the portfolio in Figure 6 on the right. This portfolio clearly separates the CS by their torque ripple values as well as by the KPI of power. It can be seen that DTA applications have a typical power range below $300 \mathrm{~W}$, whereas the EPS-motors usually operate in the range of 300 to $800 \mathrm{~W}$. 
By analysing the product portfolio one could easily figure out if it covers required areas of new applications qualitatively. Thereby the different existing market segments don't have to be considered. Subsequently experts have to check whether the selected design meets the customer requirements quantitatively.

\subsection{Discussion}

This paper presents the successful development of a data driven portfolio generation mechanism, with the industrial application of electric motors. Based on an existing product platform, different technical portfolios are created using the five steps of the method proposed by Simpson et al. (1999). By utilising the (up-front) successful implementation of a KBS including design checks as a metamodel, only feasible combinations are selected within the portfolios from the total pool of designs generated by the DoE. Using different KPIs such as the global factor of badness, costs, mechanic torque and the (relative) torque ripple, the portfolios can be evaluated generally as well as individually for each market segment or product family. By tracking any changes of the customer requirements, the portfolio can further be expanded or optimised.

A potential issue to consider is multidimensionality. For each motor, several parameters are important and in case of a specific customer request, high efforts are necessary to find the most suitable motor. In this instance, it is beneficial to use the design selector and generator mechanism presented in Tüchsen et al. (2018b). However, for the purpose of a more macroscopic view, for transparency of the capabilities, limits and possible future developments of a product platform, the proposed method is well suited.

\section{CONCLUSION AND FUTURE WORK}

In this work, a novel mechanism for data driven portfolio analysis based on product platforms using KBS is proposed. Using this method, all possible combinations of a product platform are calculated and displayed in different product portfolios. Moreover, all motor designs violating at least one of the pre-defined constraints are eliminated from the solutions pareto-fronts using acquired knowledge, design rules and by performing design checks. The product portfolio generated can be used to further expand the systems engineering collaboration and to support discussions and decision-making. The proposed mechanism is simple to extend and update by implementing new cross-sections, technologies, knowledge base and design rules. Continual portfolio analysis and update can be coupled with new product development, thus ensuring automated platform and portfolio optimisation.

\section{REFERENCES}

Breitsprecher, T. Kestel, P. Küstner, C. Spruegel, T. and Wartzack, S. (2015) "The Use of Data Mining in Modern Product Development Processes. Holistic Research for Engineers of Tomorrow", ZWF Zeitschrift fuer wirtschaftlichen Fabrikbetrieb, Vol. 110, No. 11, pp. 744-750. http://doi.org/10.3139/104.111423

Brose Fahrzeugteile GmbH and Co. KG (2018), Presentation of Business Division Drives, Würzburg, Germany.

Forza, C. and Salvador, F. (2002), "Managing for variety in the order acquisition and fulfilment process: The contribution of product configuration systems", Int. J. Production Economics, Vol. 76, pp. 87-98. http://doi.org/10.1016/S0925-5273(01)00157-8

Grünig, R. and Kühn, R. (2018), “Portfolio Analysis”, In: Grünig, R. and Kühn, R. (Eds.), The Strategy Planning Process: Analyses, Options, Projects, Springer, Berlin Heidelberg, pp. 111-136. http://doi.org/10.1007/978-3-662-56221-5

Haug, A. Hvam, L. and Mortensen, N. H. (2011), "The Impact Of Product Configurators On Lead Times In Engineering-oriented Companies", Artificial Intelligence for Engineering Design, Analysis and Manufacturing, Vol. 25, pp. 197-206. http://doi.org/10.1017/s0890060410000636

Jiao, J. R. Simpson, T.W. and Siddique, Z. (2007), "Product family design and platform-based product development: a state-of-the-art review”, Journal of Intelligent Manufacturing, Vol. 18, pp. 5-29. http://doi.org/10.1007/s10845-007-0003-2

Jinsong, Z. Qifu, W. Li, W. and Yifang, Z. (2005), “Configuration-oriented product modelling and knowledge management for made-to-order manufacturing enterprises”, Int J Adv Manuf Technol, Vol. 25, pp. 41-52. http://doi.org/10.1007/s00170-003-1871-z

Kissel, M.P. (2014), "Mustererkennung in komplexen Produktportfolios", Dissertation, Department of Mechanical Engineering, Technical University of Munich. 
Kumar, D. Chen, W. and Simpson, T.W. (2009), “A market-driven approach to product family design" International Journal of Production Research, Vol. 47, No. 1, pp. 71-104. http://doi.org/10.1080/00207540701393171

La Rocca, G. (1997), "Knowledge Based Engineering: Between AI and CAD: Review of a Language Based Technology to Support Engineering Design”, Advanced Engineering Informatics, Vol. 26, pp. 159-179. http://doi.org/10.1016/j.aei.2012.02.002

Meyer, M.H. and Lehnerd, A.P. (1997), The Power of Product Platforms: Building Value and Cost Leadership, The Free Press, New York.

Miller, T.J.E. (2002), SPEED's Electric Motors: An outline of some of the theory in the SPEED software for electric machine design, University of Glasgow.

Ortlieb, C. and Runge, T. (2017), "Assessment of Modular Platform Potential in Complex Product Portfolios of Manufacturing Companies”, Proceedings of ICED 2017 / 21 st International Conference on Engineering Design, Vancouver, Canada, August 21-25, 2017, pp. 131-139.

Ponn, J. (2015), "Portfolio Management for Electric Drives in Powertools at Hilti: Challenges and Solution Approaches" Proceedings of ICED 2015 / 20th International Conference on Engineering Design, Milan, Italy, July 27-30, 2015, pp. 105-114.

Pop, A.C. Gyselinck, J.J.C. Pinto, D.E. and Vintiloiu, I. (2017), “Optimization of Low-Power Brushless PMMachines for Automotive Applications with Focus on High Volume Mass Production", IEEE Transactions on Industrial Electronics, Vol. 64, No. 12, pp. 9767-9775. http://doi.org/10.1109/TIE.2017.2698367

Renner, I. (2007), "Methodische Unterstützung funktionsorientierter Baukastenentwicklung am Beispiel Automobil”, Dissertation, Department of Mechanical Engineering, Technical University of Munich.

Roach, G.M. and Cox, J.J. (2006), “A Case Study of the Product Design Generator”, In: Springer Simpson, T. W., Siddique, Z. and Jiao, J. R. (Eds.), Product Platform and Product Family Design: Methods and Applications, Springer, New York, pp. 499-512. http://doi.org/10.1007/0-387-29197-0_21

Simpson, T. W. Maier, J. R. and Mistree, F. (1999), “A Product Platform Concept Exploration Method for Product Family Design”, Proceedings of DETC99 / ASME Design Engineering Technical Conferences, Las Vegas, September 12-15, 1999.

Studer, R. Benjamins, V. and Fensel, D. (1998), "Knowledge Engineering: Principles and Methods", Data and Knowledge Engineering, Vol. 25, pp. 161-197. http://doi.org/10.1016/s0169-023x(97)00056-6

Styczynski, Z.A. Rudion, K. and Naumann, A. (2017), Einführung in Expertensysteme: Grundlagen, Anwendungen und Beispiele aus der elektrischen Energieversorgung, Springer, Berlin Heidelberg. http://doi.org/10.1007/978-3-662-53172-3

Tüchsen, J. Koch, M. Schleich, B. and Wartzack, S. (2018a), "Konzeption eines Assistenzsystems für die modulare und datengetriebene Entwicklung elektrischer Antriebe", 19. VDI-Kongress SIMVEC Simulation und Erprobung in der Fahrzeugentwicklung, Baden-Baden, Germany, November 20-21, 2018, VDI Wissensforum GmbH, VDI-Report 2333, pp. 801-811.

Tüchsen, J. Pop, A.C. Koch, M. Schleich, B. and Wartzack, S. (2018b), "Data Driven Design Selection and Generation - an Industrial Case Study on Electric Motors", Proceedings of the DESIGN 2018 / 15th International Design Conference, Dubrovnik, Croatia, May 21 - 24, 2018, pp. 1709-1720. http://doi.org/10.21278/idc.2018.0223

Tüchsen, J. Richter, M. Heydenreich, J. Koch, M. Schleich, B. and Wartzack, S. (2018c), "Knowledge-based and Calculation-supported Concept Validation in the Early Stages of Product Development Using the Example of the Electric Motor", Proceedings of the 4th NAFEMS DACH Conference, Bamberg, Germany, May 1416, 2018, pp. 244-248.

Ulrich, K. (1995), “The Role of Product Architecture in the Manufacturing Firm”, Research Policy, Vol. 24, pp. 419-440.

Walter, M. Breitsprecher, T. Gruber, G. and Wartzack, S. (2011), "Simulation Based Generation of an Initial Design Taking into Account Geometric Deviations and Deformations", Proceedings of ICED $2011 / 18 \mathrm{th}$ International Conference on Engineering Design, Copenhagen, Denmark, August 15-18, 2011, pp. 78-90.

Wang, Y. Ionel, D. Dorrell, D.G. and Stretz, S. (2015), "Establishing the Power Factor Limitations for Synchronous Reluctance Machines”, IEEE Transactions on Magnetics, Vol. 51, pp. 1-4. http://doi.org/10.1109/TMAG.2015.2443713 